\title{
Exploring the Pygmalion Theory for Dance Education
}

\author{
Seohee Yoon ${ }^{1}$, Sookwang $\mathrm{Choo}^{2}$ \\ ${ }^{1}$ Master's course, Dance, Pusan National University, Korea, harmony0214@naver.com \\ ${ }^{2}$ Professor, Dance, Pusan National University, Korea, choo2950@hanmail.net \\ Corresponding author: Sookwang Choo
}

\begin{abstract}
The leadership application in the field of dance education makes a big difference in learner's studying methods and results. Therefore, instructor's leadership is judged to be an important factor in dance education. As an example of the Pygmalion, leaders in modern days are also required to help people getting opportunities and achieving their own expected goals. Recently, the Pygmalion effect has been used not only in education, but also in various fields such as business management and medical care. In education, expectations of instructors toward students has been proven to be correlated to learning efficiency and results of study. However, little research has been done on the theoretical use of Pygmalion leadership in profession of dance. It is necessary to study the applicability of Pygmalion Leadership in dance education since the leadership style of dance education can greatly influence learners' performance outcome. Pygmalion effects refers to cases when one improves and achieves satisfying results by using self-fulfilling prophecy based on other's expectations and care, and the field of education has utilized this sufficiently. This study aims to extend the usage of Pygmalion leadership that was often used in psychology, pedagogy, and business administration, and seek for ways to apply theory to the field of dance education.
\end{abstract}

Keywords: Dance, Education, Leadership, Pygmalion Effect, Leadership

\section{Introduction}

In dance education, the professor's application of leadership causes a significant deviation in the learning effect of learners. Therefore, the leadership of a professor is an essential factor in dance education, which requires various experiences and senses such as expression of inner emotions, emotional interaction, and delicacy of body movements.

This leadership theory began to have an academic system from the early 20th century, and scholars have studied definitions and approaches in various ways. Stogdill et al[1] defined leadership as setting goals and influencing group actions to achieve the goals, and Blanchard[2] defined leadership as influencing the activities of individuals or groups to achieve goals in a given situation.

In the past era of authoritarianism, there was a strong perception that a leader's words were unconditionally superior. However, today's leaders need to have Pygmalion leadership to help members achieve expectations by giving them opportunities.

Recently, the Pygmalion effect has been used in education and various fields such as business and medical care. In particular, in the field of educational psychology, this method proves that teachers' expectations of students are related to the phenomenon that students' learning efficiency or results have improved. Nevertheless, research on the theoretical application of Pygmalion leadership in the field of dance is inadequate. In dance education, education on the body, movement, technique, injury prevention,

Received: July 02, 2021; $1^{\text {st }}$ Review Result: August 19, 2021; $2^{\text {nd }}$ Review Result: October 04, 2021 Accepted: November 30, 2021 
and psychological factors such as delicate emotional expression and interaction with colleagues are mainly provided.

Therefore, since the leadership style of a dance education leader can exceedingly influence learners, the researchers believe that a study on the applicability of Pygmalion leadership in dance education is necessary.

The Pygmalion effect of positive expectations through self-fulfilling prophecy refers to a phenomenon in which efficiency or results improve due to the expectations or attention of others, and educational fields actively utilize this concept.

The study conducted by Professor Robert Rosenthal of Harvard University proved the effectiveness of increasing the learning effect by instilling positive expectations of leaders toward learners. The same conclusion was made from the results of a study of students enrolled in the US Headstart Program[3].

Accordingly, this study aims to explore the possibility of applying the theory of Pygmalion leadership in dance education by expanding the Pygmalion effect, which has been mainly studied only in psychology, education, and business administration.

Research has shown that positive feedback from the instructor, opportunities provided by gradually raising the difficulty level through step-by-step learning, assistance provided by one's superior or teacher, and application of various other techniques can have positive impacts, such as psychological stress relief and improved performance. These actions are related to the behavioral aspect of Pygmalion leadership.

\section{Theoretical Background}

\subsection{Definition of Terms}

\subsubsection{Dance Education}

As a specialized education with its purpose solely on dance, it is defined as education conducted with actual dancing performances so that talents can be developed, learned, and mastered while studying what influences the learner's development of dance competency.

\subsubsection{Pygmalion Effect}

The Pygmalion effect is a psychological phenomenon wherein high expectations lead to improved performance in a given area.

\subsubsection{Leadership}

It is defined as the guidance behavior that influences activities for achieving individual or group goals and guides and induces members to increase their ability and satisfaction.

\subsubsection{Pygmalion Leadership}

Pygmalion leadership in the aspect of 'Organization-wide SFP[4]' causes the Pygmalion effect for the entire group and is defined as the leader behavior interpreted based on the Pygmalion leader behaviors composed of Rosenthal's Four Factors (Climate, Feedback, Input, Output).

\subsection{Understanding Dance Education}

The higher dimensional purpose of education today is to develop individuals based on scientific theories about human needs and abilities, and the role of education is to give students opportunities to develop themselves. Therefore, unlike other art fields, the material of dance is human itself, so dance 
education requires a thought process about the object of expression while viewing oneself objectively. As such, dance is a creative expression activity accompanied by intellectual activity. Dance education is an expressional education for self-actualization that reveals oneself through body movements.

\subsubsection{The Concept of Dance Education}

Dance, which shares origins with human history, is the most primitive art among the other art forms, and its essence lies in movement. Based on its essence, dance is a genre to express the beauty in movement by developing techniques and instilling our souls more than simply mimicking the movements of nature and animals. Human artistic ability refers to discovering human beauty by creating beauty, and materials and techniques are necessitated to express this ability concretely.

Therefore, dance education is a holistic education that nurtures desirable human beings by learning and mastering skills using the human body as a material and harmoniously developing intellectual and emotional aspects. In addition, such education has the goals of cultivating self-expression and imagination, preventing emotional stagnation, nurturing aesthetic sense, improving rhythm, and developing social behavior.

The general concept of dance education is that 'dance' being practiced in dance education is the purpose of education, which means education should focus on developing and mastering the talents for this purpose. In other words, It is a specialized education because dance itself is the purpose of education, and the form of education can be adjusted according to the ideology of education.

The goals of a leader's teaching are to improve the learner's dancing physical skills, help prevent injuries, enhance the aesthetic touch and imagination, and encourage the learner's dance skills and emotional eloquence.

In addition, dance education induces and stimulates the learner to practice dance skills, changes behavior for ideal performance, and maximizes the learner's experience. Furthermore, by examining the qualifications and responses to the learner's dance experience, the factors and answers should be explored to conjecture the process through which technological changes are made and the impact on the learner's ability to acquire technical skills.

\subsubsection{Characteristics of Dance Education}

Compared to other arts in general, the characteristic of dance lies in the expression of beauty with the human body. Therefore, intangible thoughts, such as artistic ideas, emotions, sentiments are also actualized through the body. Moreover, as people dance to express their inner self, instinctive and simple movements are inevitably suppressed. Since the educator's guidance acts as an essential factor for the wrong movements or faults of oneself and other members, the role of the leader is necessary for dance education to express beauty.

Dance education may be a part of holistic education for forming an ideal human being by improving the sense of art and promoting personality formation while learning delicate body movements and the expression of inner emotions. In comparison, dance education is recognized as a comprehensive education that transcends arts and studies in various fields, such as learning about body movements and structures, music, art, and synesthetic understanding of individuals and groups, and acting. Learners can discover and express themselves and arrive at the art of expression with a high degree of perfection.

\subsection{Understanding Pygmalion Leadership Theory}

\subsubsection{Understanding the Pygmalion Effect}

The term Pygmalion effect, a term commonly used in psychology, is derived from the name of the sculptor Pygmalion in Greek mythology, who shows that if you genuinely desire and expect something, 
you can achieve it.

A Harvard University psychologist, Robert Rosenthal, who named the Pygmalion effect, and Lenore Jacobson, who was the principal of Oak Elementary School in San Francisco, published the results of an experiment conducted at Oak Elementary School in the late 1960s in a paper in 1966 and in a book called Pygmalion in the Classroom in 1968.

After performing an intelligence test on all students, Robert Rosenthal randomly selected about 20 percent of the students regardless of the test results, gave the list to the teacher, and convinced the teacher that those had the highest potential for improving intellectual abilities and academic achievement (late bloomers). Eight months later, the same intelligence test was conducted again. As a result, the students on the list scored higher than the other students and improved significantly in school performance. These results indicate that the teachers' expectations and encouragement for the students on the list were essential factors.

In the end, the difference was not in the student's intelligence, but the 'expectation effect of the teacher,' and similar results were also found in other researchers' experiments with adults in certain organizations.

Individuals depend on the expectations of people around them, such as parents, teachers, and colleagues. When people have specific expectations for a person in an organization, he or she tends to act in a direction consistent with those expectations. However, while such an expectation alone does not achieve any result, we perform to fulfill what is expected instead[5]. Through these prior studies, the optimistic expectation delivered by the leader stimulates the learner and changes in the positive direction to produce outstanding learning results.

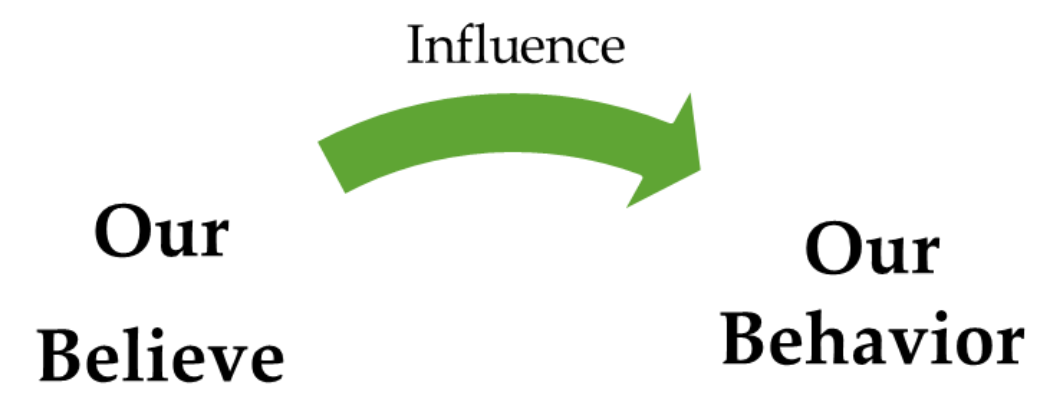

Reinforce Pygmalion Effect Impact

Others'

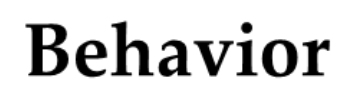

Others'

Believe

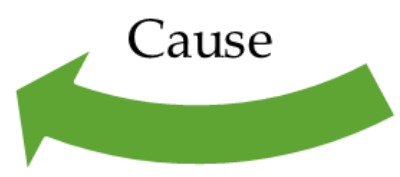

[Fig. 1] Pygmalion Effect

Prior studies on Pygmalion leadership have provided evidence for the Pygmalion effect through experiments in diverse settings schools, companies, the military, and others. 
Research on the impact of the Pygmalion effect on job satisfaction, organizational commitment, service orientation, organizational citizenship behavior, and other factors via job engagement, job involvement, learning management system (LMS), and job attitude among other parameters is being carried out in a wide range of settings, such as hotels, hospitals, and schools, and with those who have different occupations, such as athletes and social workers. Pygmalion leadership has shown to create a warm social and emotional mood, and by providing favorable feedback toward an amicable group, through which additional opportunities are provided, a favorable attitude is formed among the members of the organization.

In a similar context, Likert believed that if a manager had confidence in the personal and career development of employees, he or she would unwittingly convey such high expectations, and the employees would end up having high expectations of their own performances as a result.

This shows that the Pygmalion effect is applicable to adults, not just young elementary school students who generally have strong receptivity.

The findings of the extensive empirical research that has been carried out indicate that Pygmalion leadership can lead to the Pygmalion effect, resulting in positive influences on members.

\subsubsection{Rosenthal's Four Factor Theory[6]}

Rosenthal developed and continuously modified Pygmalion leader behaviors composed of four factors[7], including the following.

1) Climate: Teachers seem to create a warm socio-emotional atmosphere for students with high expectations. This warmth seems to communicate with the students, at least in part, through non-verbal allusions.

2) Feedback: Teachers tend to give more informative and favorable feedback, verbally and nonverbally, to students with high expectations regarding their achievements.

3) Input: Teachers seem to teach more challenging tasks to students with high expectations.

4) Output: Teachers seem to provide more opportunities for answers (responses) to students with high expectations.

\subsubsection{Creation and Application of Pygmalion Leadership}

According to Eden's research, a Pygmalion leader style is defined as a leader behavior that motivates members and influences their active efforts through positive expectations. Also, from a pedagogical point of view, a Pygmalion educator delivers positive expectations to the learner and derives the learner's excellence.

As such, the core meaning of the Pygmalion effect is positive expectations, which is also described as a self-fulfilling prophecy, raising learners' efficiency as expected by educator.

Accordingly, this paper studied the Pygmalion leadership based on the behavioral patterns of $20 \%$ of randomly selected students, who believed they were superior, as in the experimental method used in Rosenthal's study 'Pygmalion in the Classroom,' rather than differentiating between those who believe that they have a high potential for intellectual ability or academic achievement with high expectations and those who do not. This is explained as Pygmalion leadership in the aspect of 'Organization-wide SFP[4]', which causes the Pygmalion effect not only for specific group members but also for the entire group. Pygmalion leadership is defined as the leader behavior analyzed based on the Pygmalion leader behaviors composed of Rosenthal's Four Factors. 


\section{Pygmalion Leader Behavior Analysis}

\subsection{The Grounded Theory by Rosenthal's Four Factor Theory}

\subsubsection{Climate}

Climate refers to the tendency of the educator to communicate partially with the learner, mainly through the warmth and gaze exchange (eye contact), a gentle tone of voice, and body gestures, which are conveyed non-verbally. Partial communication with the learner, mainly through non-verbal suggestion, is defined as treating members more warmly and humanely.

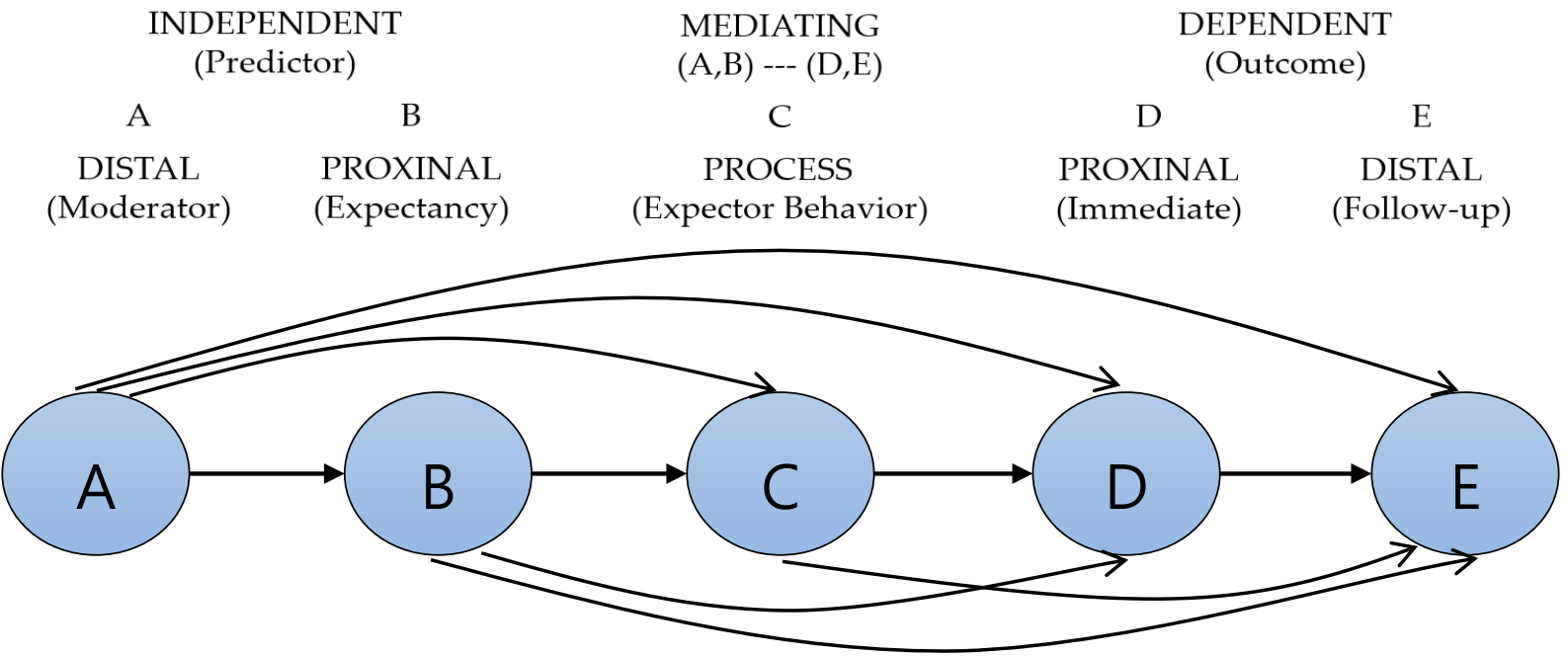

[Fig. 2] Ten-arrow Model for the Study of Interpersonal Expectancy Effects

In other words, Climate mainly includes non-verbal communication in addition to verbal factors, such as using polite titles to learners, explaining and guiding them gently and warmly, and waiting for tasks. This term generally refers to behaviors related to the positive emotions experienced by the learner.

When it comes to the importance of the instructor's nonverbal communication in dance, it is noteworthy that the instructor can connect with the students through the way he or she looks at them and his or her gestures, not just through the physical language of dance, in a dance class. The instructor can also help students express themselves through movement based on spatial awareness.

In other words, in order for the instructor's nonverbal communication to help form a connection with the students and, at the same time, allow students to express their thoughts and emotions threedimensionally, the nonverbal behavior must be conveyed to the students directly. Therefore, in dance education, it is necessary to recognize the importance of non-communication for instructors in playing their leadership role in order to draw out their students' potential and help them express themselves emotionally.

\subsubsection{Feedback}

Feedback states that educators tend to implement more informative and favorable feedback regarding achievement to learners with positive expectations. It is defined as a task in which the educator appropriately responds to the learner's learning behavior and informs the individual of the behavioral progress or the reaction result.

In other words, feedback refers to the learner's verbal and non-verbal improvement behavior and 
includes various responses to the learner, such as frequent and specific praise, encouragement, and correction of tasks.

Dance education requires meticulous teaching and correction, and it is the instructor's behavior and feedback that can enable students to perfect their expressivity in their dance performances. It is also noteworthy that instructors need to enhance student satisfaction and their interest in the class, as it in turn leads to goal attainment.

Prior research has also reported that positive feedback from the instructor has a positive impact on psychological factors, such as intrinsic motivation and class satisfaction, among students.

\subsubsection{Input}

Input refers to the amount of information given to the learner, and the educator refers to more complex tasks for learners with high expectations. It is defined as giving more important information or tasks to learners by teaching them more and more challenging tasks. In other words, input refers to providing high-quality information in more diverse ways, giving significant or challenging tasks, and teaching new things to learners.

Aside from practice, another factor that is necessary for acquiring the dance techniques taught concerns the various information that is communicated during practice. Dancers in training come across a wide range of information when learning new movements, and such information is one of the most essential elements of dance practice and is necessary for improving one's performance skills.

\subsubsection{Output}

Output refers to giving members of high expectations more frequent and extended opportunities to respond. It is defined as providing positive opportunities for recognition by inducing and leading the learners to demonstrate their learning ability and transferring authority to members. The response time of the educator to the learner's question is also increased to give more opportunities related to the learner's achievement and show the ability. Educators give more opportunities to voice their opinions by asking questions or providing hints and related information materials to elicit accurate answers.

As an output, learners can gain confidence, which is vital to ballet and executing the movements, and are better able to wholly employ their skills, without fearing failure. Moreover, as the instructor provides students with more opportunities to display their skills, it allows them to freely express themselves and boosts their involvement, satisfaction, and learning participation in their major.

\section{The Necessity of Pygmalion Leadership for Dance Education}

In dance education, in particular, all kinds of outcomes can be expected, depending on the leadership style of the instructor, and in some cases, the risk of injury can be unusually high. This is one of the reasons it is important to examine the kind of leadership that the instructors exert when educating and training their students.

The recent trend of dance education maintains a horizontal relationship with students rather than relying on absolute authority or traditional apprenticeship-based education, leading to greater respect from students and stimulating the desire and passion for voluntary learning[8].

As such, expectations for dance education educators are not only in teaching skills but also understanding and empathizing with participants. In other words, it is necessary to understand the object that can be recognized as the material (element) of expression[9].

As a result of analyzing the four Pygmalion-leader behaviors for dance education and exploring their applicability, the positive suggestion of the educator helps to form a good learning emotion and atmosphere for the learners. In addition, reliable communication between learners and leaders plays an 
integral part in dance education, and mutual communication can be facilitated. Therefore, mutual sympathy helps express movement through better spatial awareness.

In addition, the behavior of the educator who mainly teaches dance and the feedback with the students facilitates high-quality expression, granting continuity to reach the goal by inducing satisfaction and interest in the class[10]. In particular, the feedback given during practice reduces the learner's unnecessary actions for trial and error and suggests a direction for future improvement. Many studies have been conducted on how feedback affects learners and whether there is a limit to increase the learning effect. Most of these studies revealed that feedback in the teaching-learning process dramatically affects learning and academic achievement[11].

In addition, learners can prevent injuries during practice by clearly communicating and organizing their learning priorities. Educators provide information and education on training or practice methods in more specific and diverse ways to motivate the learners to set goals and fulfill more diverse efforts to achieve goals. With more opportunities to demonstrate their abilities, learners have the opportunity to express themselves freely, increase their participation in learning and their confidence, which is an integral part of showing performance, and do their best without fear of failure.

As a result of previous studies, it was found that Pygmalion leadership is necessary and appropriate for the application, especially in dance education, where leadership is crucial. Therefore, the researchers believe that it is necessary to apply Pygmalion leadership in the role of a dancer to have expectations, give opportunities, and help them achieve in the age of knowledge service.

\section{Conclusion}

This study was conducted to explore the applicability of the Pygmalion leadership theory for dance education.

The purpose of this study is to examine the meaning and necessity of analysis of Pygmalion leadership for the effectiveness of dance education and provide a foundation for applying the method of Pygmalion leadership theory in the actual field by proposing its applicability.

Dance education aims to prioritize improving the learner's dance skills and preventing injuries through delicate education while appreciating the learner's learning capability, body structure, and learning intention. Therefore, the educator's leadership theory is a vital factor in dance education.

Also, the mutual relationship between the educator and the learner is an integral factor in dance education as the learner's learning effect shows a significant deviation depending on the educator's leadership.

By developing and analyzing Pygmalion leadership behavior as four factors, Rosenthal was able to research on the relationship between educators and learners, learners' academic emotion and task continuity, and class satisfaction in the field of pedagogy beyond psychology. Therefore, the necessity of applying Pygmalion leadership theory in dance education is as follows.

First, Rosenthal's Pygmalion leadership theory analyzes the leadership of a dance leader more accurately by introducing four factors: Climate, Feedback, Input, and Output.

Second, leadership theory is constantly changing with the flow of the times and the approaches of researchers. By analyzing and studying dance education through Rosenthal's Four Factor theory on Pygmalion leadership, we can identify the characteristics of dance leaders more accurately and guide more effective dance education in the future.

Third, if we apply Pygmalion leadership theory to observe the leader's language, behavior, gestures and record the educational process in the dance education process, we can provide the connection and objectivity of dance education. In addition, if the analysis is done through the four-factor theory of leadership behavior, it can be helpful to the dance education process as it is possible to accurately know the learning efficiency of the learner according to the leadership style. 
The purpose of the application of Pygmalion leadership theory is to provide better educational services by applying and operating various educational methods, based on the learner's learning process, by finding the clues for the educator to prevent injuries and improve the dancer's ability and continuity.

Dance educators are required to form leadership virtues that give opportunities and help them achieve by showing and conveying expectations to the learners based on the theory of the Pygmalion effect. It is necessary to seek specific research methods and various approaches in the future regarding the Pygmalion theory application in dance education.

The limitations and suggestions of this study are as follows.

As the Pygmalion leadership theory has a broad scope and contains many implications, this study may not have dealt with the complete set of the theory in terms of content. Also, Pygmalion leader behavior is divided into four or six factors depending on the trend and different scholars' perspectives. This paper analyzed and explored the applicability of Pygmalion leader behavior in dance education with Rosenthal's Four Factor theory and emphasis on the researcher's primary areas. Therefore, this study may possess a limitation regarding Pygmalion leadership based on six factors.

In this paper, the applicability of Pygmalion leadership in dance education was explored as a method of interpreting Pygmalion leadership in terms of organization-wide SFP that causes the Pygmalion effect not only for specific members of the group but also for the entire group. Therefore, the applicability of Pygmalion leadership interpreted in terms of the interpersonal contrast effect, the opposite concept of this study, may pose a limitation of this study.

In addition, since analysis and research were conducted based on literature rather than empirical research, there may be partial limitations in its application in actual dance education.

Accordingly, future research on dance education based on the theory of Pygmalion leadership should be conducted with robust and empirical analysis on the improvement of learners' academic ability, academic satisfaction, and continuity that dance instructors and learners undergo in dance education.

\section{References}

[1] S. Kerr, C. A. Schriesheim, C. J. Murphy, R. M. Stogdill, Toward a contingency theory of leadership based upon the consideration and initiating structure literature, Organizational Behavior and Human Performance, (1974), Vol.12, No.1, pp.62-82, DOI: 10.1016/0030-5073(74)90037-3

[2] K. H. Blanchard, P. Zigarmi, D. Zigarmi, Leadership and The One Minute Manager, William Morrow, (1985), ISBN: 978-0-06-230944-0

[3] R. Rosenthal, L. Jacobson, Pygmalion in the classroom: Teacher expectation and pupils' intelligence development, Holt, Rinehart \& Winston, (1968), ISBN: 978-0-03-068805-8

[4] D. Eden, Pygmalion without interpersonal contrast effects: Whole groups gain from raising manager expectations, Journal of Applied Psychology, (1990), Vol.75, No.4, pp.394-398, DOI: 10.1037/0021-9010.75.4.394

[5] D. Eden, Leadership and expectations: Pygmalion effects and other self-fulfilling prophecies in organizations, The Leadership Quarterly, (1992), Vol.3, No.4, pp.271-305, DOI: 10.1016/1048-9843(92)90018-B

[6] R. Rosenthal, Interpersonal expectancy effects: A 30-yeat perspective, Current Directions in Psychological Science, (1994), Vol.3, No.6, pp.176-179, DOI: 10.1111/1467-8721.ep10770698

[7] Park In-Yang, The Effect of the Hotel Pygmalion Leadership on LMX and the Organization Immersion, Department of Tourism Business Management, The Graduate School of Kyonggi University, Doctoral Dissertation, (2009)

[8] Sung Ji-sun, A study on the effect of professor's emotional intelligence perceived by ballet majoring University students on self-efficacy, learning satisfaction, and academic persistence attitude, Resach of Dance Education, (2021),Vol.32, No.1, pp.187-206, DOI: 10.23022/kdes.2021.32.1.187 
[9] Hwang Jeong-ok, The role and potentiality of contemporary dance education experts (Dance animateurs), Resach of Dance Education, (2017), Vol.28, No.4, pp.5-18, ISSN: 1229-3547

[10] Hwang Jung-A, The Influence of Perceived Learning Environments on Subject Interest, Dankook University, Department of Dance Graduate School, Master Thesis, (2010)

[11] Seon Yeon-Hee, A Study on Self-Efficacy and Self-Esteem by the Feedback Types of Practical Dance instructorFocused on Academic Credit Bank System, Kookmin University, Graduate School of Total Arts, Master Thesis, (2019) 